\title{
Mixed Conduction of Proton and Electron in Tungsten Phosphate Glass and Its Hydrogen Transport
}

\author{
Satoru Fujitsu ${ }^{1}$ and Hiroshi Kawazoe ${ }^{2}$ \\ ${ }^{1}$ Dept. of Materials Science and Ceramic Technology, Shonan Institute of Technology \\ Tsujido-Nishikaigan, Fujisawa, Kanagawa, 251-8511 Japan \\ ${ }^{2}$ Kawazoe Frontier Technology, Inc., Kuden, Sakae-ku, Yokohama, Kanagawa \\ 247-0014, Japan
}

Keywords: hydrogen, mixed conductor, phosphate glass, proton, concentration cell

\begin{abstract}
The transference number of protons and the hydrogen transport behavior through tungsten phosphate glass have been measured through the use of a concentration cell. Based on measurement of the electrical motive force by changing the hydrogen partial pressure of both sides of a specimen glass kept in the concentration cell, the ionic transference number was estimated to be $48 \%$. When one side is kept in hydrogen and the other in nitrogen, hydrogen transport is observed and its quantity is accelerated by applying a positive dc bias on the hydrogen side. After applying the dc bias continuously for over $1 \mathrm{~h}$, the hydrogen transport is abruptly increased with no cracks and the hydrogen flux is $1.5 \times 10^{-3} \mu \mathrm{molcm}^{-2} \mathrm{~s}^{-1}$.
\end{abstract}

\section{INTRODUCTION}

It is well established that protons are a major ionic carrier in melt-quenched phosphate glass, which has been contaminated by water vapor in the ambient environment[1-3]. Abe et al.[4] have reported that proton conductivity can be increased to $10^{-2} \mathrm{Scm}^{-1}$ at $100^{\circ} \mathrm{C}$ for glasses with higher $\mathrm{OH}$ concentrations. In addition, a power generation density of $5 \mathrm{~mW} / \mathrm{cm}^{2}$ at RT was obtained for a fuel cell, that had a structure similar to that of the ordinary PEMFC except with phosphate glass replacing the polymer electrolyte.

Tawarayama et al.[5-7] have reported that tungsten phosphate glasses $\left(30 \mathrm{NaO}_{1 / 2}-10 \mathrm{BaO}-10 \mathrm{WO}_{3}-\right.$ $20 \mathrm{NbO}_{5 / 2}-30 \mathrm{PO}_{5 / 2}$ ) show the unique properties, with water vapor and hydrogen molecules being dissociated at the glass surface and the generated hydrogen atoms being selectively dissolved into the glasses by the reaction with $\mathrm{W}^{6+}$ ions at a temperature below $\mathrm{T}_{\mathrm{g}}\left(570^{\circ} \mathrm{C}\right): \mathrm{H}+\mathrm{W}^{6+}=\mathrm{H}^{+}+\mathrm{W}^{5+}$. The possible application of the glasses as a hydrogen production membrane from water vapor and hydrogen purifying membrane at a mid temperature region $\left(300-500^{\circ} \mathrm{C}\right)$ was suggested. They prepared a reaction cell composed of one end of a sealed Pd tube, whose outside surface was coated with a thick film of glass. Nitrogen gas saturated with water vapor was fed to the glass coated surface, while the inside of the tube was connected to the vacuum line with a Q-mass. Dissociation of water molecules and flux of the dissolved hydrogen through the glass membrane was estimated to be $5 \times 10^{-6} \mu \mathrm{molcm}^{-2} \mathrm{~s}^{-1}[8]$.

It has been well accepted that hydrogen permeates the solid phase either by diffusion or dissociative transfer. In the former case, hydrogen dissolves in a free volume or cage in the solids and jumps into neighboring free spaces. A typical example is the permeation of hydrogen in silica glasses which is the least dense solid having an $\mathrm{SiO}_{2}$ composition. In the latter mechanism, hydrogen is dissolved in the solids by ionizing into a proton and an electron, and both species jump into available sites semi-independently. Mixed conductors with high protonic and electronic conductivities are suitable for obtaining solid materials of high gas transportability[9].

In the present study, the transference number of proton (and an electron) of the tungsten phosphate glasses was determined by the concentration cell method. Also reported will be a unique observation that hydrogen flux through the glass plate is enhanced by application of a dc field to the 
two Pd coated surfaces, which are exposed to the ambient environment with high and low partial pressures of hydrogen, respectively.

\section{EXPEIMENTAL PROCEDURE}

\section{Glass preparation}

The reagent-grade powders $\left(\mathrm{Na}_{2} \mathrm{CO}_{3}, \mathrm{NaPO}_{3}, \mathrm{Ba}\left(\mathrm{PO}_{3}\right)_{2}, \mathrm{WO}_{3}\right.$, and $\mathrm{Nb}_{2} \mathrm{O}_{5}$ ) were employed as starting materials. Mixed powder $\left(33 \mathrm{NaO}_{1 / 2}-10 \mathrm{BaO}-20 \mathrm{NbO}_{5 / 2}-10 \mathrm{WO}_{3}-27 \mathrm{PO}_{5 / 2}\right)$ was melted in a Pt crucible at $1200^{\circ} \mathrm{C}$ for $3 \mathrm{~h}$ and then quenched in the carbon die. To remove the internal strain, the glass was annealed at $500^{\circ} \mathrm{C}$ for $1 \mathrm{~h}$.

\section{Effect of Atmosphere on Electrical Conduction}

This glass was cut into a rectangular plate $(10 \times 10 \times 5 \mathrm{~mm})$ and the two $10 \times 10$ surfaces were mirror-finished. Palladium film was coated on both sides of the specimen $(10 \times 10 \mathrm{~mm}$ face) by the vacuum evaporation method. It is well known that a hydrogen molecule is decomposed by $\mathrm{Pd}$ and that the generated hydrogen atom is dissolved into Pd, after which the $\mathrm{Pd}$ films are used for accelerating the dissolution of hydrogen atoms into the glass plate[10]. The current through the glass specimen under a dc bias of $5 \mathrm{~V}$ was measured in dry air, dry $\mathrm{N}_{2}$, and $\mathrm{N}_{2}$ containing $6 \%$ of $\mathrm{H}_{2}\left(\mathrm{~N}_{2}-\mathrm{H}_{2}(6 \%)\right)$ at $500^{\circ} \mathrm{C}$.

\section{Measurement of the Ionic Transference Number}

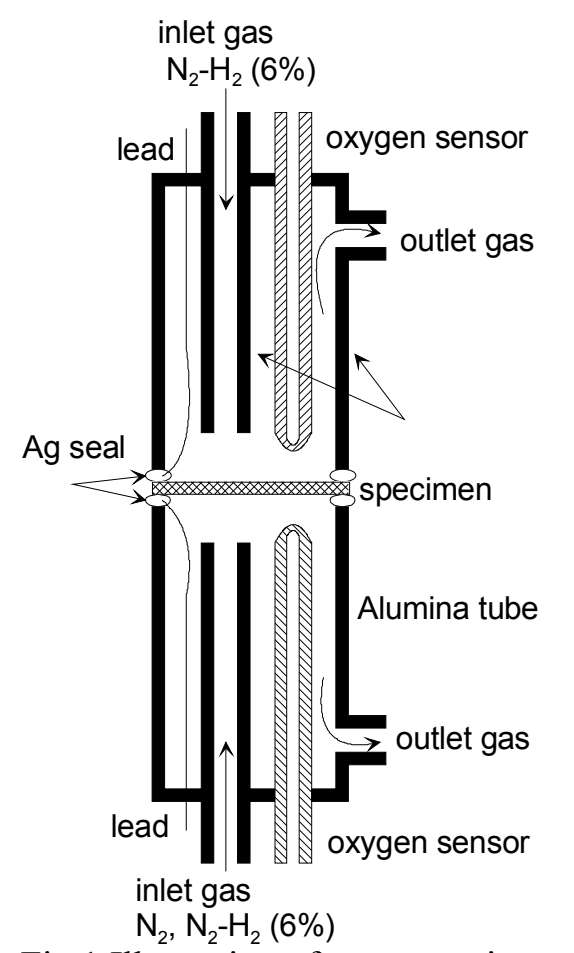

Fig.1 Illustration of concentration cell.

The Pd-coated disk specimen with a diameter of $30 \mathrm{~mm}$ and a thickness of $2 \mathrm{~mm}$ was sandwiched by two alumina tubes with $\mathrm{Ag}$ seal rings, as illustrated in Fig. 1 . This cell was kept at $500^{\circ} \mathrm{C}$ and the electrical motive force between the electrodes was measured with changing the hydrogen partial pressure in the lower chamber of the cell in Fig. 1.

\section{Measurement of Hydrogen Transport}

The specimen was assembled in the same manner as that used for determining the ionic transference number, as described above. A constant flow of gas $(200 \mathrm{ccm})$ of $\mathrm{N}_{2}-\mathrm{H}_{2}(6 \%)$ and $\mathrm{N}_{2}$ was fed into the upper and lower part at $500^{\circ} \mathrm{C}$, respectively. The dc bias was applied on the specimen. Hydrogen transport from the $\mathrm{N}_{2}-\mathrm{H}_{2}(6 \%)$ side to the $\mathrm{N}_{2}$ side was measured based on the change in the oxygen partial pressure $\left(\mathrm{pO}_{2}\right)$ measured by the stabilized zirconia oxygen sensor put on the $\mathrm{N}_{2}$ side. The $\mathrm{pO}_{2}$ decreased in response to the reaction of $\mathrm{O}_{2}$ with the hydrogen transported to the $\mathrm{N}_{2}$ side; $\mathrm{H}_{2}+1 / 2 \mathrm{O}_{2}=\mathrm{H}_{2} \mathrm{O}$.

\section{RESULTS AND DISCUSSION}

\section{Change of Electrical Current by Changing Atmosphere}

Figure 2 shows the current of the glass under the dc bias of $5 \mathrm{~V}$ at $500^{\circ} \mathrm{C}$. In the initial stage, dry air was supplied. As seen in the figure, the current decreased monotonically. Considering the composition of glass, it is judged that the charge carrier was $\mathrm{Na}^{+}$and that the decrease in current was due to the ionic polarization of $\mathrm{Na}^{+}$. When the atmosphere was changed to nitrogen at $3500 \mathrm{~s}$, the current decreased slightly. After returning the atmosphere to dry air at $4800 \mathrm{~s}$, the current returned to the extrapolated line for dry air atmosphere. This change in current with the change in atmosphere is similar to the behavior of p-type semiconducting oxides: the conductivity decreases with decreasing $\mathrm{pO}_{2}$. Upon the introduction of $\mathrm{N}_{2}-\mathrm{H}_{2}(6 \%)$ into the system at $6200 \mathrm{~s}$, the current 
increased steeply and the decrease in current as that in air by polarization was not observed. The presence of ion blocking by the electrode in air was also suggested from the result of the complex impedance measurements shown in Fig. 3. The rise in the plot was on the low-frequency side (dot circle in Fig. 3), which means that ion blocking was observed in the measurement under air. From these results, it is judged that the main carrier in air is $\mathrm{Na}^{+}$(over 95\%), and that those in $\mathrm{N}_{2}-\mathrm{H}_{2}(6 \%)$ are $\mathrm{H}^{+}$, electrons and/or holes that are not blocked by the Pd electrode.

\section{Ionic Transference Number}

The electrical motive force is plotted in Fig. 4 in relation to changes in the ratio of the hydrogen partial pressure of the upper and lower chambers in Fig. 1. The specimen was pre-annealed in $\mathrm{N}_{2}-\mathrm{H}_{2}(6 \%)$ ) for $5 \mathrm{~h}$ at $500^{\circ} \mathrm{C}$. The ionic transference number $\left(t_{i}\right)$ was estimated using Nernst's equation,

$$
V_{E M F}=t_{i} \frac{R T}{2 F} \ln \left(\frac{p H_{2}(\text { ref })}{p H_{2}(\text { meas })}\right)
$$

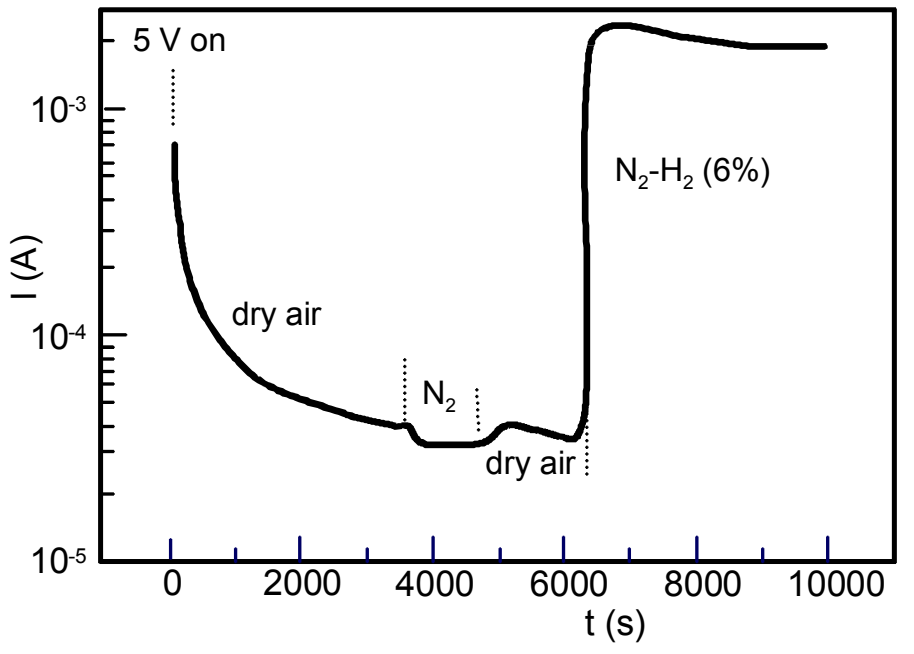

Fig.2 Change in current under DC bias (5V) with changing in atmosphere.

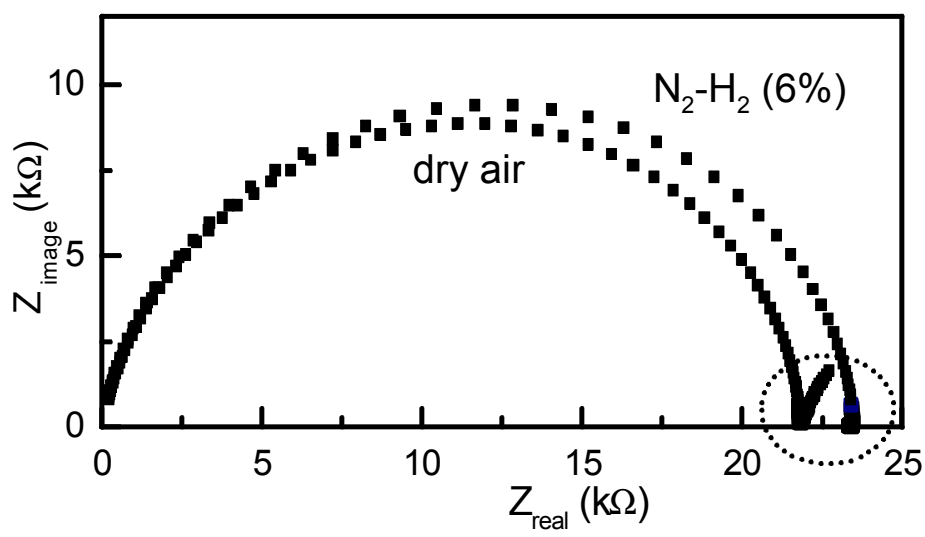

where $V_{E M F}$ refers to the electrical motive force and the other symbols have general meanings. The $\mathrm{N}_{2}-\mathrm{H}_{2}(6 \%)$ was used as the reference $\left(\mathrm{pH}_{2}(\mathrm{ref})=6000 \mathrm{~Pa}\right)$ and the ambient environment on the other side $\left(\mathrm{pH}_{2}\right.$ (meas)) was prepared by mixing the $\mathrm{N}_{2}-\mathrm{H}_{2}(6 \%)$ and $\mathrm{N}_{2}$. From the plot shown in Fig. 4, the $t_{i}$ was estimated to be $48 \%$. This glass was then concluded to be a mixed conductor of ionic and electronic. Though it is expected that protons are the main ionic carrier in $\mathrm{N}_{2}-\mathrm{H}_{2}(6 \%)$ rather than $\mathrm{Na}^{+}$, the quantitative estimation has not been carried out yet.

\section{Hydrogen Transport}

The change in the flux of hydrogen in response to changing the applied dc bias was monitored by the change in $\mathrm{pO}_{2}$ on $\mathrm{N}_{2}$ side and is shown in Fig. 5. The applied bias was increased in a stepwise manner from $0 \mathrm{~V}$ to $6 \mathrm{~V}$, and the $p O_{2}$ decreased little by little with increases in the applied bias from $50 \mathrm{~Pa}$ to $2 \mathrm{~Pa}$. At $11000 \mathrm{~s}$, when the applied voltage was $8 \mathrm{~V}$, the $\mathrm{pO}_{2}$ decreased abruptly to $10^{-16} \mathrm{~Pa}$. By releasing the applied bias, the $p O_{2}$ increased to $10^{-14} \mathrm{~Pa}$. To attain this $\mathrm{pO}_{2}$ for this cell system, approximately $0.01 \mathrm{ccm}$ of $\mathrm{H}_{2}$ should be added to $200 \mathrm{ccm}$ of $\mathrm{N}_{2}$ flow. From this rough estimation, the flux in hydrogen is predicted to be $1.5 \times 10^{-3} \mu_{\mathrm{molcm}}^{-2} \mathrm{~s}^{-1}$. 
This value is 2 orders of magnitude larger than that reported by Tawarayama et al[8]. They measured hydrogen transference for this glass without applying dc bias. The most important factor in producing the large enhancement of hydrogen transport is thought to be application of the $\mathrm{dc}$ bias. Though the value of flux obtained here is smaller than that reported by Matsumoto et al. for $\mathrm{BaCe}_{0.9-\mathrm{x}} \mathrm{Y}_{0.1} \mathrm{Ru}_{\mathrm{x}} \mathrm{O}_{3-\delta}$ of protonic and electronic mixed conductor $\left(6 \times 10^{-2} \mu \mathrm{molcm}^{-2} \mathrm{~s}^{-1}\right.$ at $800^{\circ} \mathrm{C}$ ) [11], it is thought that the glass obtained here is promising as a hydrogen transport material from the

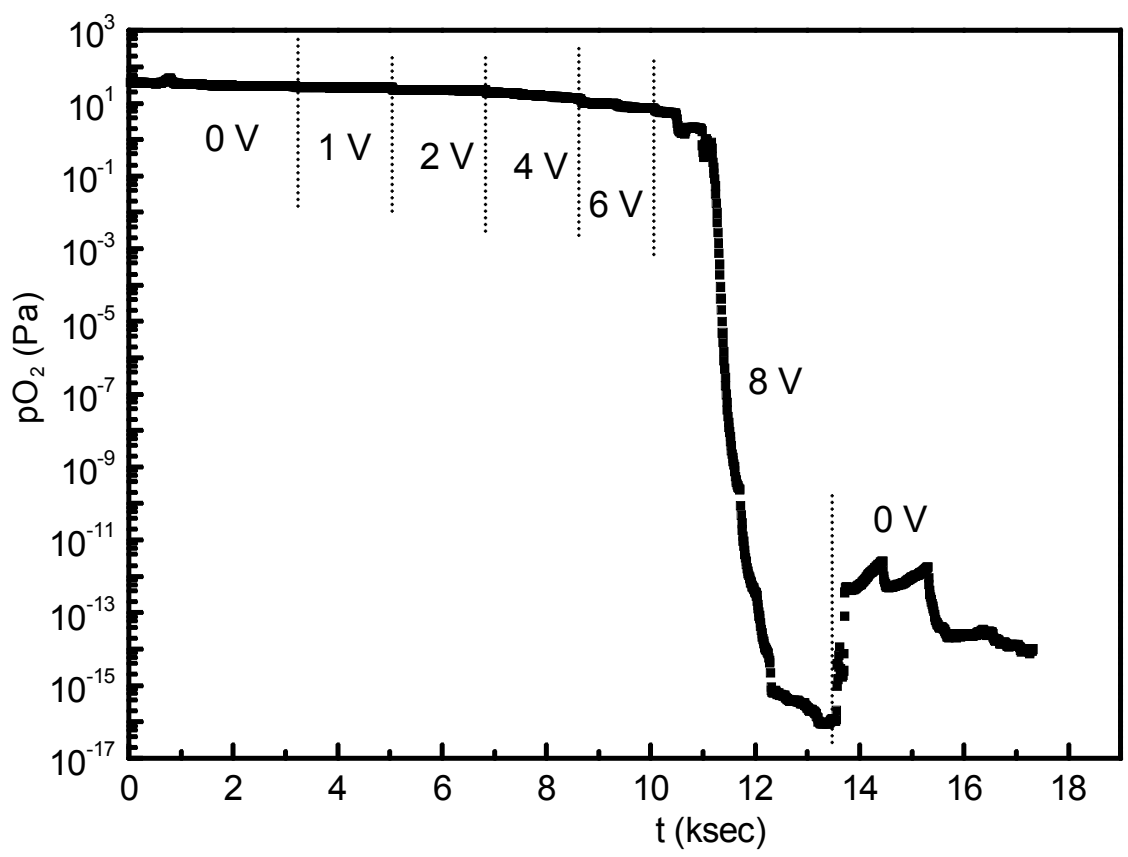

Fig. 5 Change in oxygen partial pressure in $\mathrm{N}_{2}$ side.

By transference of hydrogen to $\mathrm{N}_{2}$ side, the $\mathrm{pO}_{2}$ decreses by chemical equilibrium of $\mathrm{H}_{2}+1 / 2 \mathrm{O}_{2}=\mathrm{H}_{2} \mathrm{O}$. perspective of not only hydrogen transference but also the easy preparation of glass materials and the lower driving temperature.

\section{SUMMARY}

1. The protonic and electronic mixed conducting glass was prepared by the conventional melting - quenching method.

2. The protonic conduction expressed by penetrating the hydrogen into the glass and its ionic transference number was estimated to be $48 \%$.

3. The hydrogen transference through the glass was observed by using the concentration cell method and its flux was estimated to be $1.5 \times 10^{-3} \mu \mathrm{molcm}^{-2} \mathrm{~s}^{-1}$.

\section{REFERENCES}

[1] Yoshihiro Abe, Hideo Hosono, Yoshio Ohta and L. L. Hench, Phys. Rev. B, 38 (1988), p.10166.

[2] H. Hosono, T. Kamae and Y. Abe, J. Am. Ceram. Soc., 72 (1989), p.294.

[3] K. Kotama, K. Nakanishi, H. Hosono and Y. Abe, J. Electrochem. Soc., 138 (1991), p.2928.

[4] Y. Abe, M. Hayashi, T. Iwamoto, H. Sumi and L. L. Hench, J. non-Cryst. Solid, 351 (2005), p.2138.

[5] H. Tawarayama, F. Utsuno, H. Inoue, H. Hosono and H. Kawazoe, Chem. Mater., 18 (2006), p. 2810 .

[6] H. Tawarayama, S. Sugata, H. Inoue, H. Hosono and H. Kawazoe, Chem. Mater., 19 (2007), p.4385.

[7] S. Fujitsu, Proceedings of The Ninth International SAMPE symposium, (2005), p. 442.

[8] H. Tawarayama, F. Utsuno, H. Inoue, S. Fujitsu and H. Kawazoe, J. Power Sources 161 (2006), p.129.

[9] I. Reiss, Solid State Ionics, 157 (2001), p.1.

[10] G. Adachi and Y. Sakaguchi, Method to Separate Hydrogen by Metal Membrane (in Japanese), In Advanced Technology of Hydrogen Energy, ed. T. Ohta, NTS, Tokyo, 1995, p.149.

[11] H. Matsumoto, T. Shimura, T. Higuchi, H. Tanaka, K. Katahira, T. Otake, T. Kudo, K. Yoshiro, A. Kaimai, T. Kawada and J. Mizusaki, J. Electrochem. Soc., 152 (2005), p.A488. 